\title{
Patients with Advanced Disease: The Value of Patient Reported Outcomes
}

\author{
Jan Gaertner ${ }^{a, b}$ Gerhild Becker ${ }^{a, b}$ \\ aDepartment of Palliative Care, University Medical Center Freiburg, \\ ${ }^{\text {b} C o m p e t e n c e ~ C e n t e r ~ P a l l i a t i v e ~ C a r e ~ B a d e n-W u ̈ r t t e m b e r g ~(K O M P A C T), ~ F r e i b u r g ~ i . B r ., ~ G e r m a n y ~}$
}

In this issue of Oncology Research And Treatment, Jürg Bernhard and colleagues [1] present quality of life (Qol) data, findings from other patient reported outcome measures (PRO) and performance status assessments from a randomized controlled trial (RCT) of patients with advanced pancreatic cancer (median survival of their patients was 7-8 months). Survival data and other findings of the RCT have been reported earlier [1,3]. Jürg Bernhard and his co-authors emphasize the value of measuring PRO and Qol of the patients to assess the actual benefit that patients may expect from disease modifying interventions in this incurable and life-limiting phase of the disease. They argue that in contrast to 'tumor centered outcomes' [1] such PRO and Qol measures are essential for a patient centered assessment of treatments' effect on patients' survival and wellbeing. In their study they specifically assessed whether 'clinical benefit response' (CBR), a combined measure of performance status, pain intensity, and body weight is associated with survival, and whether CBR reflects a wideenough range of domains to adequately capture patients' perception. The article adds substantially to the ongoing debate about the meaningful assessment of the effects of disease modifying interventions on the patients' Qol and other PRO [4].

Meanwhile, the importance of thorough Qol and PRO assessments in clinical trials has been recognized by the public, leading research organizations, and drug approval authorities [5]. Notably, the present work of Bernhard et al. [1] was supported by both public and private funding. This may reflect the fact that also physician-researchers and pharmaceutical companies are increasingly interested in this topic [5].

Especially when caring for patients with advanced and lifelimiting diseases, preserving Qol and reducing symptom burden are among the most important therapeutic goals [6]. This is not restricted to end-of-life care. Yet, it is equally important if the patients are in a good condition and still receive disease modifying interventions with a primarily life-prolonging intention [6]. A current survey among Europeans from different countries revealed that patients, relatives, and healthy interviewees highly value Qol if faced with terminal illness [7]. Unfortunately, it has also been reported that clinical trials

\section{KARGER}

Fax +497614520714

Information@Karger.com

www.karger.com (c) 2014 S. Karger GmbH, Freiburg

2296-5270/14/0372-0007\$39.50/0

Accessible online at:

www.karger.com/ort from the field of advanced cancer care largely neglect the measurement of Qol and other PRO but almost exclusively rely on the measurement of survival and surrogate measures, such as progression free survival (PFS) [8,9]. Even if Qol and other PRO are obtained in clinical trials, reporting and appraisal of these findings is frequently insufficient [8,9]. Paradoxically, the publication process of the randomized controlled trial SAKK 44/00-CECOG/PAN.1.3.001 [3] that provided the data base for the study presented by Bernhard et al. [1] is a classic example. Although Qol and PRO data were obtained in the trial, authors of the primary publication did not report these findings [3]. The specific reasons for this are unclear, but obviously other findings were considered to be more important. Instead of Qol and PRO, the working group chose to publish other findings from the available secondary endpoints. This reflects common practice and should not be judged as a mistake of the working group around Bernhard and Herrmann. For example, even European Organization for Research and Treatment of Cancer (EORTC) working groups frequently decide on a step-by-step (sliced) publication strategy and separately publish the Qol and survival data of their elaborate RCT, as in extremely relevant multicenter EORTC trials about the effects of adjuvant whole brain radiotherapy $[10,11]$.

As stated above, in the primary publication of the trial SAKK 44/00-CECOG/PAN.1.3.001 by Herrmann et al. [3], findings for surrogate measures, such as PFS, were reported. PFS is a traditional and very frequently chosen primary or secondary outcome parameter in clinical trial protocols [12]. In the diction of Bernhard et al. [1], PFS is a classic choice of a 'tumor-centered outcome'. The widespread use of PFS in advanced cancer trials is not unproblematic, especially if it is used as the primary endpoint [12]. A study for the U.S. Department of Health and Human Services, Agency for Healthcare Research and Quality [12] reported that contradictory to physicians' and researchers' intuition, a correlation of PFS and overall survival is questionable for many cancers. The same was reported for the earlier assumption that PFS might correlate with Qol or psychological wellbeing. 
Similar considerations as for Qol and other PRO are applicable for the patients' performance status (which strictly speaking is another PRO). The performance status is a main component of the CBR assessed by Bernhard et al. [1]. The patients' performance status is well known to be one of the most important prognostic indicators for the realistic benefits and harms patients may expect from disease modifying interventions in advanced disease [13]. It has been argued that patients with a lower Karnofsky or Eastern Cooperative Oncology Group (ECOG) score are at considerably higher risk of experiencing side effects from disease modifying therapies while they are less likely to benefit in terms of survival [13]. Although in clinical practice patients with ECOG 3 frequently receive such treatments, trials rarely provide data about the effect of these therapies on patients with such a rather reduced performance status [13]. This severely impedes a patient-centered shared decision-making process, since the information is essential to weigh the patients' odds for experiencing benefits or harms from the available interventions [13].

The value of Qol and other PRO as reported by Bernhard et al. [1] is not only relevant for the research setting, but also for clinical practice. For example, Velikova et al. [14] reported that the mere addition of a comprehensive patient reported Qol measurement to the set of routine assessments (e.g. laboratory and radiologic testing) helps to increase the quality of cancer care. Meanwhile, the evidence base for such an approach is broad and the routine assessment of symptom burden, distress and/or Qol has been advocated by major treatment guidelines [6,15]. Despite such evidence it should not be overlooked that currently few centers adhere to these recom- mendations $[16,17]$. This is surprising, since for example the National Comprehensive Cancer Network (NCCN) has developed easy-to-use single item scales for this purpose [18].

Bernhard et al. should be congratulated for increasing our awareness for the value of Qol and other PRO measures in the care for patients with advanced and life-limiting disease. In the past years, 'personalized therapy' (in a genomic understanding) has become one of the main sources of truly meaningful progress in the care for these patients. Similarly, the routine adoption of PRO and Qol measures in trials and everyday practice may substantially add to the 'personalization' (in the sense of individualization) of care. Routinely weighing the impact of the available treatment option on the physical, psychological, social, and spiritual wellbeing of our patients will eventually lead to an even more patient-centered way of care.

\section{Disclosure Statement}

Jan Gaertner received research support from public funding (Federal Ministry of Education and Research, Germany) and private funding by pharmaceutical companies (Sanofi-Aventis, Mundipharma, TEVA/ Cephalon), honoraria for lectures from pharmaceutical companies (Mundipharma, Grünenthal, Pfizer, Cephalon, TEVA, Archimedes), and has served on advisory boards for buccal Fentanyl (TEVA/Cephalon). Gerhild Becker received research support from public funding (Federal Ministry of Education and Research, Germany, German Cancer Aid) and private funding by pharmaceutical companies (Roche Pharma, Novartis Pharma, Mundipharma). She received honoraria for lectures from pharmaceutical companies (Mundipharma, Grünenthal, Pfizer, Cephalon) and she serves on an advisory board for Naloxegol (Astra Zeneca ).

\section{References}

1 Bernhard J, Dietrich D, Glimelius B, Bodoky G, Scheithauer W, Herrmann R: Clinical benefit response in pancreatic cancer trials revisited. Oncol Res Treat 2014;37: DOI: 10.1159/000357965.

2 Bernhard J, Dietrich D, Scheithauer W, Gerber D, Bodoky G, Ruhstaller T, et al.: Clinical benefit and quality of life in patients with advanced pancreatic cancer receiving gemcitabine plus capecitabine versus gemcitabine alone: a randomized multicenter phase III clinical trial--SAKK 44/00-CECOG/ PAN.1.3.001. J Clin Oncol 2008;26:3695-3701.

3 Herrmann R, Bodoky G, Ruhstaller T, Glimelius B, Bajetta E, Schüller J, et al.: Gemcitabine plus capecitabine compared with gemcitabine alone in advanced pancreatic cancer: a randomized, multicenter, phase III trial of the Swiss Group for Clinical Cancer Research and the Central European Cooperative Oncology Group. J Clin Oncol 2007; 25:2212-2217.

4 Booth CM, Ohorodnyk P, Eisenhauer EA: Call for clarity in the reporting of benefit associated with anticancer therapies. J Clin Oncol 2009;27:e213e214.

5 Rock EP, Scott JA, Kennedy DL, Sridhara R, Pazdur R, Burke LB: Challenges to use of health-related quality of life for Food and Drug Administration approval of anticancer products. J Natl Cancer Inst Monogr 2007:27-30.

6 Levy MH, Adolph MD, Back A, Block S, Codada SN, Dalal S, et al.: Palliative care. J Natl Compr Cancer Netw JNCCN. 2012;10:1284-1309.
7 Higginson IJ, Gomes B, Calanzani N, Gao W, Bausewein C, Daveson BA, et al.: Priorities for treatment, care and information if faced with serious illness: A comparative population-based survey in seven European countries. Palliat Med 2013 doi: $10.1177 / 0269216313488989$ [Epub ahead of print].

8 Amdal CD, Jacobsen AB, Guren MG, Bjordal K: Patient-reported outcomes evaluating palliative radiotherapy and chemotherapy in patients with oesophageal cancer: a systematic review. Acta Oncol 2013;52:679-690.

9 Friedlander ML, King MT: Patient-reported outcomes in ovarian cancer clinical trials. Ann Oncol 2013;24 Suppl 10:x64-x68.

10 Soffietti R, Kocher M, Abacioglu UM, Villa S, Fauchon F, Baumert BG, et al.: A European Organisation for Research and Treatment of Cancer phase III trial of adjuvant whole-brain radiotherapy versus observation in patients with one to three brain metastases from solid tumors after surgical resection or radiosurgery: quality-of-life results. J Clin Oncol 2013;31:65-72.

11 Kocher M, Soffietti R, Abacioglu U, Villà S, Fauchon F, Baumert BG, et al.: Adjuvant wholebrain radiotherapy versus observation after radiosurgery or surgical resection of one to three cerebral metastases: results of the EORTC 2295226001 study. J Clin Oncol 2011;29:134-141.

12 Gutman SI, Piper M, Grant MD, Basch E, Oliansky DM, Aronson N: Progression-free survival: what does it mean for psychological well-being or quality of life? [Internet]. Rockville (MD): Agency for Healthcare Research and Quality (US); 2013 [cited 2014 Jan 5]. Available from: http://www.ncbi. nlm.nih.gov/books/NBK137759/

13 Niraula S, Seruga B, Ocana A, Shao T, Goldstein R, Tannock IF, et al.: The price we pay for progress: a meta-analysis of harms of newly approved anticancer drugs. J Clin Oncol 2012;30:3012-3019.

14 Velikova G, Keding A, Harley C, Cocks K, Booth L, Smith AB, et al.: Patients report improvements in continuity of care when quality of life assessments are used routinely in oncology practice: secondary outcomes of a randomised controlled trial. Eur J Cancer 2010;46:2381-2388.

15 Rangachari D, Smith TJ: Integrating palliative care in oncology: the oncologist as a primary palliative care provider. Cancer J 2013;19:373-378.

16 Peppercorn JM, Smith TJ, Helft PR, Debono DJ, Berry SR, Wollins DS, et al.: American society of clinical oncology statement: toward individualized care for patients with advanced cancer. J Clin Oncol 2011;29:755-760.

17 Glare P, Plakovic K, Schloms A, Egan B, Epstein AS, Kelsen D, et al.: Study using the NCCN guidelines for palliative care to screen patients for palliative care needs and referral to palliative care specialists. J Natl Compr Cancer Netw. 2013;11:1087-1096.

18 Dabrowski M, Boucher K, Ward JH, Lovell MM, Sandre A, Bloch J, et al.: Clinical experience with the NCCN distress thermometer in breast cancer patients. J Natl Compr Canc Netw 2007;5:104-111. 